\title{
Chemoprevention of dietary digitoflavone on colitis-associated colon tumorigenesis through inducing Nrf2 signaling pathway and inhibition of inflammation
}

Yang Yang ${ }^{1}$, Xueting Cai ${ }^{1}$, Jie Yang ${ }^{1}$, Xiaoyan Sun ${ }^{1}$, Chunping Hu' ${ }^{1}$ Zhanpeng Yan ${ }^{1}$, Xiaojun Xu², Wuguang Lu', Xiaoning Wang ${ }^{1}$ and Peng Cao ${ }^{1,2^{*}}$

\begin{abstract}
Background: Nuclear factor-erythroid 2-related factor 2 (Nrf2) has emerged as a novel target for the prevention of colorectal cancer (CRC). Many chemopreventive compounds associated with Nrf2 activation are effective in preclinical systems and many on-going clinical trials are showing promising findings. In present study we evaluated the cytoprotective effect and chemopreventive properties of dietary digitoflavone.

Method: A cell based Antioxidant Response Element (ARE)-driven luciferase reporter system was applied to screen potential Nrf2 activators. Activation of Nrf2 by digitoflavone was confirmed through mRNA, protein and GSH level assay in Caco-2 cell line. The cytoprotective effect of digitoflavone was evaluated in $\mathrm{H}_{2} \mathrm{O}_{2}$-induced oxidative stress model and further signaling pathways analysis was used to determine the target of digitoflavone induced Nrf2 activation. An AOM-DSS induced colorectal cancer model was used to assess the chemopreventive effect of digitoflavone.
\end{abstract}

Result: Micromolarity $(10 \mu \mathrm{M})$ level of digitoflavone increased Nrf2 expressing, nuclear translocation and expression of downstream phase II antioxidant enzymes. Furthermore, digitoflavone decreased $\mathrm{H}_{2} \mathrm{O}_{2}$-induced oxidative stress and cell death via p38 MAPK-Nrf2/ARE pathway. In vivo study, $50 \mathrm{mg} / \mathrm{kg}$ digitoflavone significantly reduced AOM-DSS induced tumor incidence, number and size.

Conclusion: These observations suggest that digitoflavone is a novel Nrf2 pathway activator, and protects against oxidative stress-induced cell injury. The results of the present study add further evidence of the molecular mechanisms that allow digitoflavone to exert protective effects and reaffirm its potential role as a chemopreventive agent in colorectal carcinogenesis.

Keywords: Digitoflavone, Luteolin, Reactive oxygen species (ROS), Nrf2, p38 MAPK, Chemoprevention

\section{Introduction}

Gastrointestinal tract is body's digestion and absorption organ and frequently faces the challenges from xenobiotics and endogenous toxic substances-induced oxidative stress due to its particular location and function. Also, Reactive Oxygen Species (ROS) are involved in many

\footnotetext{
* Correspondence: pcao79@yahoo.com

'Laboratory of Cellular and Molecular Biology, Jiangsu Province Institute of Traditional Chinese Medicine, 100\#, Shizi Street, Hongshan Road, Nanjing 210028, Jiangsu, China

${ }^{2}$ State Key Laboratory of Natural Medicines, China Pharmaceutical University, 24 Tongjiaxiang, Nanjing 210009, Jiangsu, China
}

physiological functions and colorectal pathological processes, such as Crohn's disease, ulcerative colitis, and colorectal cancer $(\mathrm{CRC})$ [1-3]. Therefore, there is an increasing interest in the potential effects of exogenous antioxidants on the prevention of oxidative gastrointestinal disorders. Recently, Up-regulation of endogenous antioxidant and phase II antioxidant enzymes by Nrf2 has emerged as a novel target for the prevention of CRC since it is currently well accepted that chronic inflammation is a contributing factor in $15-20 \%$ malignancies including CRC [4] and that this inflammation can be 
attributed to a number of factors including oxidative stress, reactive oxygen species (ROS) and reactive nitrogen species (RNS).

Phase II metabolizing-detoxifying and antioxidant defense enzymes [such as $\mathrm{NADP}(\mathrm{H})$ quinone oxidoreductase 1 (NQO-1), heme oxygenase-1 (HO-1), and aldo-keto reductase1 subunits $\mathrm{C}-1$ ( AKR1C1), C-2 ( AKR1C2) and C-3 (AKR1C3) ], antioxidants [such as $\gamma$-glutamylcysteine synthetase catalytic subunit $(\gamma-\mathrm{GCSc}), \gamma$-glutamylcysteine synthetase modifier subunit $(\gamma-\mathrm{GCSm})$, glutathione reductase (GR), thioredoxin reductase (TR) and peroxiredoxin (Prx)], and ATP-dependent drug efflux pumps [ATP- binding cassette, subfamily $\mathrm{C}(\mathrm{CFTR} / \mathrm{MRP})$ members (ABCC2, $\mathrm{ABCC}, \mathrm{ABCC} 4)$ ] are regulated by cis-acting regulatory element-the antioxidant responsive element (ARE; $5^{\prime}$-(A/ G) TGACNNNGC(A/G) -3') [5], and Nrf2, a member of the Cap'n' Collar family of transcription factors, which mainly regulates transcriptional activation through the ARE [6]. The Nrf2/ARE signal pathway has been considered to protect cells against carcinogenesis and attenuate cancer development via neutralization of ROS or carcinogens [7,8]. Nrf2-deficient mice were more susceptible to carcinogenesis, suggesting that Nrf2/ARE mediates the phase II detoxifying enzymes and antioxidant proteins in the inactivation of chemical carcinogens [9].
Functional foods act as antioxidant nutrients and protect against many human chronic diseases by combating reactive oxygen species (ROS) generation $[10,11]$. As diet antioxidants, flavonoids, polyphenolic compounds occurring naturally in the plant kingdom such as vegetables, fruits and plant-derived beverages such as tea, cocoa, and red wine, display a wide range of pharmacological properties, including anti-carcinogenesis and anti-inflammation [12]. Flavonoids also exert a potent antioxidant activity, acting as reactive oxygen species (ROS) scavengers, metal ions chelators and free radical reaction terminators [13]. However, they can also act indirectly as antioxidants stimulating phase II detoxifying and antioxidant defense enzymes to preserve cellular integrity and tissue homeostasis [14]. Digitoflavone (3, 0, 4, 5, 7-tetrahydroxyflavone, Figure 1A), a flavone subclass of flavonoids, vegetables and fruits such as celery, parsley, broccoli, onion leaves, carrots, peppers, cabbages, apple skins, and chrysanthemum flowers are digitoflavone rich [15-18]. Plants rich in digitoflavone have been used as Chinese traditional medicine for hypertension, inflammatory diseases, and cancer [19]. Also, it has been known to have chemopreventive effects against malignant tumors in vivo [20,21]. Our recent study has found digitoflavone induce G2 phase cell cycle arrest, inhibit angiogenesis and down-regulate expression<smiles>O=c1cc(-c2ccc(O)c(O)c2)oc2cc(O)cc(O)c12</smiles>
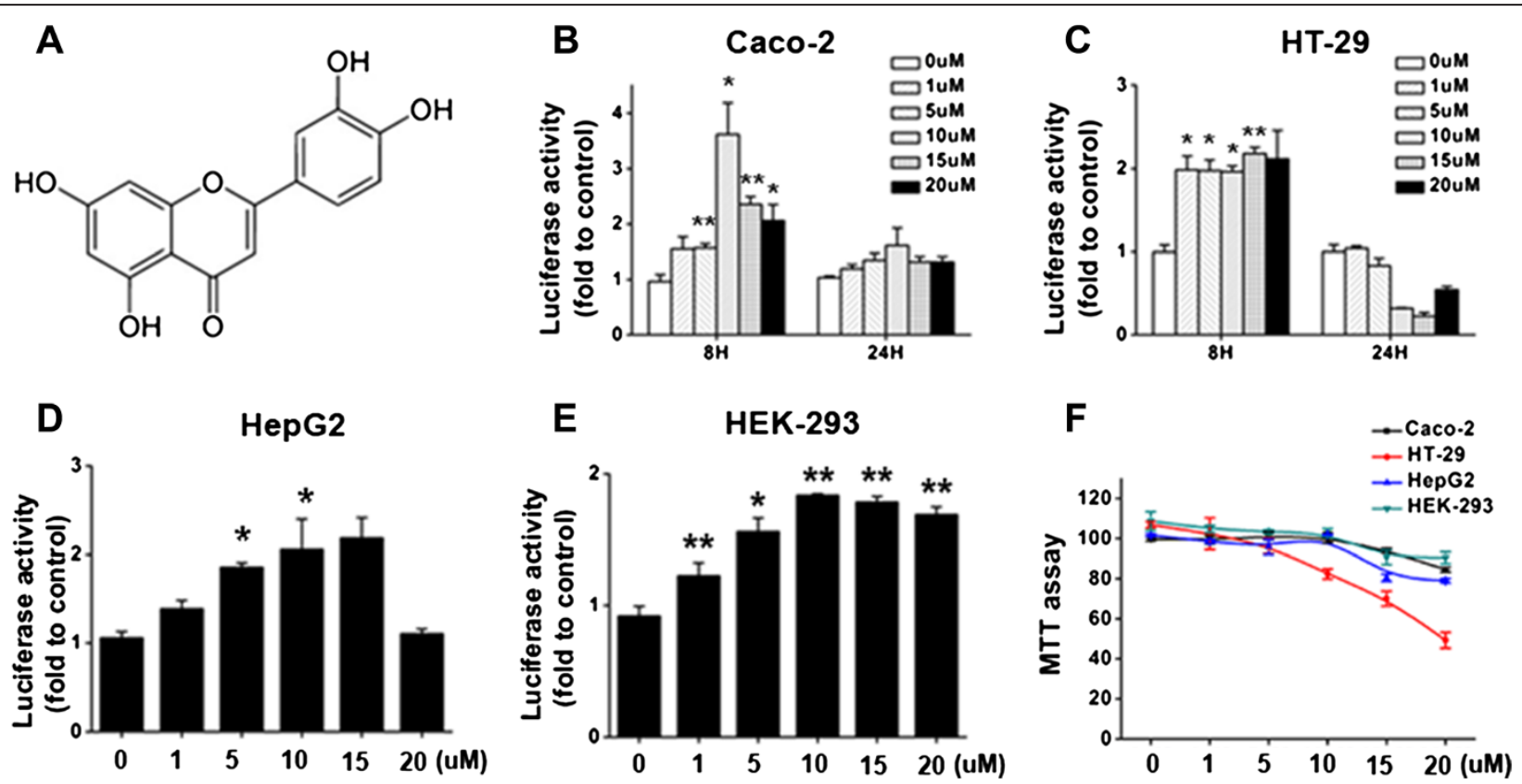

Figure 1 Effects of digitoflavone on ARE-luciferase activity. (A) Chemical structure of digitoflavone (3, 0, 4, 5, 7-tetrahydroxyflavone). Its molecular weight is 286.23. (B-C) Effects of digitoflavone on ARE-luciferase activity in Caco-2 and HT-29 cells. Caco-2 cells were treated with various concentrations of digitoflavone for 8 hours and 24 hours respectively, luciferase activity was assayed as described in Materials and Methods. (D-E) HEK-293 cells, HepG2 cells were treated with various concentrations of digitoflavone for 8 hours and luciferase activity were assayed as described in Materials and Methods. (F) Cell viability of digitoflavone in Caco-2, HT-29, HepG2 and HEK-293 cells. Cells were treated with various concentrations $(1-20 \mu \mathrm{M})$ of digitoflavone for 24 hours, cell viability were determined using MTT assay. Values were expressed as mean \pm SD of triplicate experiments. Significantly different (versus control group): * $p<0.05$ and ${ }^{* *} p<0.01$. 
of NF-kB [22-24]. Much attention has been focused on digitoflavone due to its strong antioxidant and radical scavenging properties [25]. However, as a diet compound, digitoflavone's antioxidant function on gastrointestinal tract is not fully understood.

In the present work, we have investigated the action of digitoflavone to protect Caco-2 cells, a human cell line originating from gastrointestinal tract that retains many of the morphological and enzymatic features typical of normal human enterocytes, against oxidative stress and further in vivo study of its chemopreventive effect in AOMDSS induced CRC model. Our results demonstrate for the first time that digitoflavone is able to attenuate oxidative injury in colonic cells by up-regulate the expression of the antioxidant defense enzymes via a mechanism that involved p38 MAPKs activation and Nrf2 translocation and further confirmed chemopreventive effect by free radical scavenging and inhibition of inflammation.

\section{Result}

Digitoflavone induced high levels of ARE-driven luciferase activities in Caco-2, HT-29, HepG2 and HEK-293 cells

A DNA fragment containing 8 copies of the ARE sequence (GTGACAAAGCACCC) were subcloned into the pGL3 vector. After transient transfection with the expression plasmid, different concentrations of digitoflavone were added to the cell culture and incubated for 8 hours and 24 hours respectively. Parallel cell viability assays revealed no obviously cytotoxic effects ( $>95 \%$ viability) for the digitoflavone treatment when the concentration of digitoflavone is lower than $10 \mu \mathrm{M}$ in Caco-2, HepG2, HEK-293 cells and $5 \mu \mathrm{M}$ in HT-29 cells (Figure 1F). $10 \mu \mathrm{M}$ digitoflavone induced the highest level of luciferase activity after 8 hours exposure, about 5-fold increases of control (Figure 1B). Another human epithelial colorectal adenocarcinoma cell line HT-29 also showed that low concentrations $(5 \mu \mathrm{M})$ of digitoflavone can increase the ARE-luciferase activity with no obviously cytotoxic effects (Figure 1C). To evaluate the ARE-driven luciferase activity of digitoflavone in other cell lines, HepG2 (Figure 1D) and HEK-293 (Figure 1E) cell lines were transient transfected with the pGL3-ARE-luciferase plasmid respectively and tested with 1-20 $\mu \mathrm{M}$ digitoflavone for 8 hours. All tested cell lines showed over 2-fold increases of the luciferase activity at $1-10 \mu \mathrm{M}$ concentrations of digitoflavone. These result suggested that digitoflavone, at low concentrations $(<10 \mu \mathrm{M})$, is a potent activator of the Nrf2/ARE antioxidant pathway.

\section{Digitoflavone stimulated the expression of the Nrf2-ARE-mediated antioxidant defense proteins in Caco-2 cells}

To verity whether activation of luciferase activity by digitoflavone in Caco-2 cells reflected the expression of the endogenous ARE-driven genes, the mRNA levels of GR, TR, HO-1, $\gamma$-GCSc, $\gamma$-GCSm, NQO1, and MRP2 were examined in the presence or absence of digitoflavone. In Caco-2 cells treated with $10 \mu \mathrm{M}$ digitoflavone for 8 hours, the mRNA levels of GR, TR, HO-1, $\gamma$-GCSc, $\gamma-$ GCSm, UGT1A1 and UGT1A10 increased 1.2-, 6.0-, 1.5, 1.7-, 1.8-, 1.5, 1.8-fold, respectively (Figure 2A). Similarly, evaluation of the Nrf2-mediated antioxidant enzymes, such as $\gamma$-GCSc and TR by Western blotting showed that exposure of Caco-2 cells to 1-15 $\mu \mathrm{M}$ digitoflavone strongly induced $\gamma$-GCSc, $\gamma$-GCSm and TR protein expression in a dose and time-dependent manner (Figure 2).

\section{Digitoflavone induced Nrf2 protein expression and nuclear translocation}

Previous studies described that under normal conditions, Keap1 sequestered Nrf2 in the cytoplasm and that translocation of Nrf2 into the nucleus is essential for the transactivation of various targeted genes [26,27]. Therefore, to further investigate effects of digitoflavone one the Nrf2/ARE activation, we examined the protein expression and subcellur location of Nrf2 in Caco-2 cells after digitoflavone treatment. As show in the Figure 2B, Western blot analysis demonstrated a significant increase of Nrf2 protein expression after digitoflavone treatment in dose- and time-dependent manner. Western blot analysis of the nuclear fraction (Figure 2C) and Immunofluorescence analyses (Figure 2D) showed Nrf2 accumulation in the nucleus of Caco-2 cells after digitoflavone treatment.

To confirm the requirement of Nrf2 in the digitoflavoneinduced antioxidant activities, we transfected the Caco-2 cells with Nrf2 target siRNA before digitoflavone treatment. As show in Figure 2E, silencing Nrf2 expression significantly inhibited the digitoflavone-induced $\gamma$-GCSc, $\gamma$ GCSm and TR up-regulation, suggesting that digitoflavone induced antioxidant activities in an Nrf2/ARE-dependent manner.

We also investigated changes in GSH content in Caco2 cells after incubation in varying concentrations of digitoflavone for $8 \mathrm{~h}$. Digitoflavone increased GSH content and decreased the level of GSSG in a dose-dependent manner, which resulted in a dose-dependent increase in the ratio of GSH/GSSG (Figure 2F-H). This result is consistent with increased levels of $\gamma$-GCSc and $\gamma$-GCSm mRNAs, which encode the rate-limiting enzymes in GSH synthesis, in Caco-2 cells.

\section{Digitoflavone exhibited cytoprotective effects against $\mathrm{H}_{2} \mathrm{O}_{2}$-induced oxidative stress in Caco-2 cells}

Nrf2 is a key component in protection against carcinogenesis and oxidative stress [26,28,29]. Previous reports have suggested that oxidative stress plays an important 


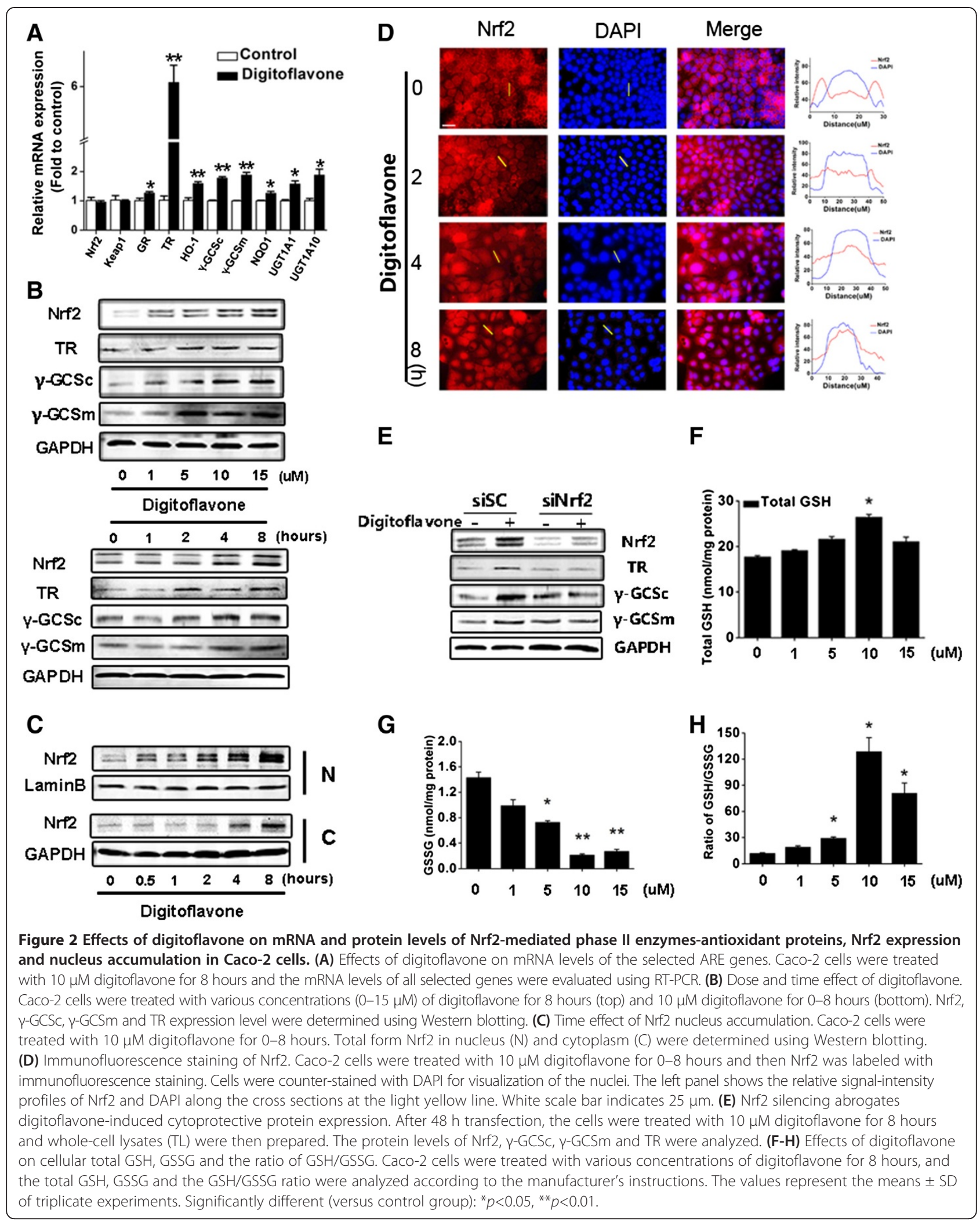


role in tumor promotion [30,31]. $\mathrm{H}_{2} \mathrm{O}_{2}$ may induce selfgeneration of free radicals known as the ROS-induced ROS release at the mitochondrial level [32], which has been widely used as a model of exogenous oxidative stress. In this study, we validated if antioxidant activities induced by digitoflavone can actually protect against $\mathrm{H}_{2} \mathrm{O}_{2}$-induced damage in Caco- 2 cells. The protective effects of digitoflavone against the $\mathrm{H}_{2} \mathrm{O}_{2}$-induced cytotoxicity were detected by MTT assay. As show in Figure 3A and B, pretreatment of digitoflavone for $4 \mathrm{~h}$ exhibited dose-dependent protective effects in the $\mathrm{H}_{2} \mathrm{O}_{2}$-damage model and the Nrf2 target siRNA transfection group (Figure 3C), while the GSH synthesis inhibitor BSO partially abolished the digitoflavone-induced protective effect (Figure 3D).
Intracellular ROS levels affect cell viability and high ROS levels can cause cellular damage. Using flow cytometry analysis, we examined the effects of digitoflavone on intracellular ROS levels. As shown in Figure $3 \mathrm{E}$ and $\mathrm{F}$, $\mathrm{H}_{2} \mathrm{O}_{2}$ treatment led to a significant increase in ROS levels. Statistical analysis showed that digitoflavone reduced the $\mathrm{H}_{2} \mathrm{O}_{2}$-induced intracellular ROS level in a dose-dependent manner. We further confirmed the anti-apoptotic effects of digitoflavone through the quantitative analysis of FITCAnnexin V/PI staining by flow cytometry. In the normal control group, the percentage of apoptotic cells was $8.7 \%$. The percentage of apoptotic cells increased up to $33.9 \%$ in the $\mathrm{H}_{2} \mathrm{O}_{2}$ model group (Figure $3 \mathrm{G}$ and $\mathrm{H}$ ). The protective effects of digitoflavone against cell apoptosis was

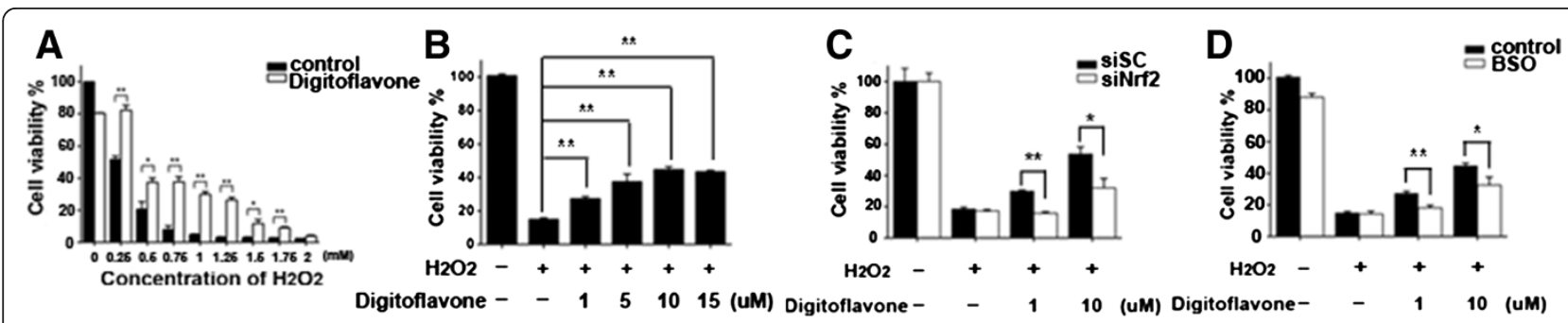

E

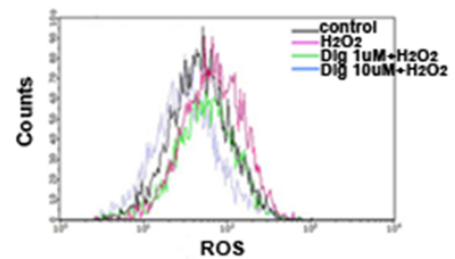

$\mathbf{F}$

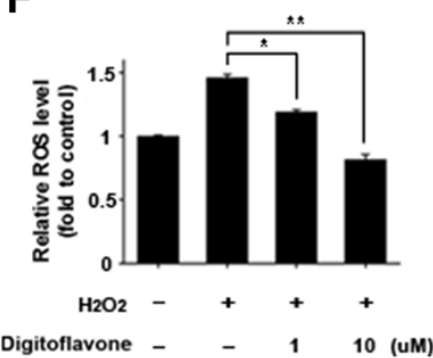

G
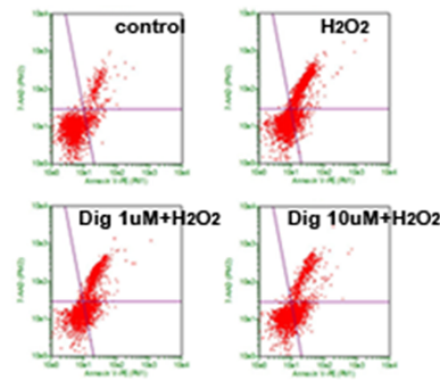

H

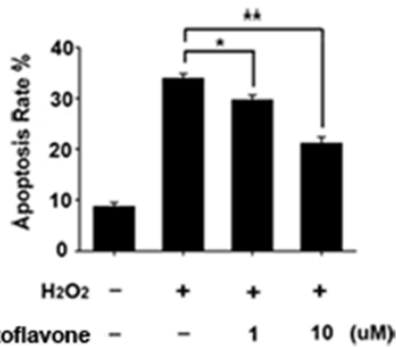

Figure 3 Effects of digitoflavone on oxidative stress-induced cell injury in Caco-2 cells. (A) The anti-oxidative ability of digitoflavone. Caco-2 cells were pretreated with $10 \mu \mathrm{M}$ digitoflavone for 4 hours then espoused to various concentration of $\mathrm{H}_{2} \mathrm{O}_{2}$ for an additional $24 \mathrm{~h}$. Cell viability was determined using MTT assay. (B) Dose-dependent anti-oxidative ability of digitoflavone. Caco-2 cells were pretreated with 1-15 $\mu \mathrm{M}$ digitoflavone for 4 hours then espoused to $500 \mathrm{\mu M} \mathrm{H}_{2} \mathrm{O}_{2}$ for an additional $24 \mathrm{~h}$. Cell viability was determined using MTT assay. (C) Nrf2 silencing partly abrogates digitoflavone-induced cytoprotective effect. After $48 \mathrm{~h}$ transfection, the cells were treated with $10 \mu \mathrm{M}$ digitoflavone for 4 hours and followed an oxidative stress of $500 \mu \mathrm{M} \mathrm{H}_{2} \mathrm{O}_{2}$ for 24 hours, Cell viability was determined using MTT assay. (D) GSH synthetise inhibitor-BSO partly abrogates digitoflavone-induced cytoprotective effect. Caco-2 cells were pretreated with $10 \mu \mathrm{M}$ BSO for 2 hours, then cells were treated with $10 \mu \mathrm{M}$ digitoflavone for an additional 4 hours, anti-oxidative ability was tested with $500 \mu \mathrm{M} \mathrm{H} \mathrm{H}_{2}$ for an additional $24 \mathrm{~h}$ using MTT assay. (E) Flow cytometry analysis of the intracellular ROS. Caco-2 cells were treated with various concentrations of digitoflavone for 4 hours before espoused to $500 \mathrm{MM} \mathrm{H}_{2} \mathrm{O}_{2}$ for an additional $4 \mathrm{~h}$. Intracellular ROS levels were measured using DCF fluorescence. (F) Statistical analysis of the flow cytometry date. (G) Flow cytometry analysis of the apoptotic rate. Caco-2 cells were treated with various concentrations of digitoflavone for 4 hours before espoused to $500 \mu \mathrm{M} \mathrm{H}_{2} \mathrm{O}_{2}$ for an additional $6 \mathrm{~h}$. cells were stained with FITC-Annexin V-PI, flow cytometry measured the apoptotic rate. (H) Statistical analysis of the apoptotic rate. The values represent the means \pm SD of triplicate experiments. Significantly different: ${ }^{*} p<0.05,{ }^{* *} p<0.01$. 
concentration dependent (apoptosis rate $29.7 \pm 0.88 \%$ and $21.2 \pm 1.18 \%$ for 1 and $10 \mu \mathrm{M}$ digitoflavone treatment respectively).

\section{Role of p38 MAPK in the digitoflavone-induced Nrf2-ARE} activation in Caco-2 cells

Under normal conditions, the interaction of Nrf2 with the Kelch-like ECH-associated protein 1 (Keap1) traps Nrf2 in the cytosol, leading to a rapid degradation of the cytosolic Nrf2 by the $26 \mathrm{~S}$ proteasome, via the Cullin3based E3-ligase ubiquitination complex [26]. A number of studies have shown that several signaling pathways, including PI3K [33,34], MAPK [35,36], and PKC [37,38], are involved in the induction of $\mathrm{Nrf} 2 / \mathrm{ARE}$-driven gene expression. To elucidate the signal transduction pathways leading to the activation of $\mathrm{Nrf} 2$ and the induction of antioxidants expression in the digitoflavone-treated cells, we examined the effects of digitoflavone on the expression of Keap1 and the phosphorylation of PKC, AKT, ERK1/2, and p38 MAPK. Upon digitoflavone treatment, time-dependent increases in the phosphorylation of AKT, ERK1/2, and p38 MAPK were observed (Figure 4A). To determine whether such activations of AKT, ERK1/2, and p38 MAPK contribute to the digitoflavone-induced Nrf2 activation, several kinase inhibitors, including wortmannin (for PI3K), PD98059 (for MEK1/2), and SB202190 (for p-p38 MAPK), were employed. As show in Figure 4B-D, inhibition of the phosphorylation of AKT and ERK1/2 did not decrease the digitoflavone-induced Nrf2 activation.
However, the p38 MAPK inhibitor SB202190 significantly inhibited the digitoflavone-induced Nrf2 activation (Figure 5A) and nuclear accumulation (Figure 5B). To determine whether such activation of p38 MAPK contribute to the digitoflavone-mediated protections against the cytotoxic effects of $\mathrm{H}_{2} \mathrm{O}_{2}$, the Caco- 2 cells were pre-incubated with SB202190 for 2 hours before the 4 hours digitoflavone treatment, Cells were then challenged with $500 \mu \mathrm{M} \mathrm{H} \mathrm{H}_{2} \mathrm{O}_{2}$ for additional $24 \mathrm{~h}$ for MTT assay, $4 \mathrm{~h}$ for ROS detection, and $6 \mathrm{~h}$ for apoptosis detection, respectively. As show in Figure 5C, SB202190 eliminated the protective effects of digitoflavone. SB20 2190 also reversed the digitoflavone antioxidant activity (Figure 5D and E). Further, the anti-apoptosis ability of digitoflavone was also abolished by SB202190 (Figure 5F and $\mathrm{G})$.

\section{The chemopreventive effect of digitoflavone on tumor progression in mice}

We further explored chemopreventive effects of digitoflavone on tumor progression by administering it to mice from week 2 to day 13, after the AOM and 3 cycles of DSS treatments (Figure 6A). Compared with the AMO group, digitoflavone treatment reduced the numbers and size of macroscopical tumors remarkably and the shorted colon length was resvered by digitoflavone when compared with AOM group, also less loss of crypts was observed in mice with digitoflavone treatment (Figure 6B-D). Next, activation of Nrf2 and its downstream targets
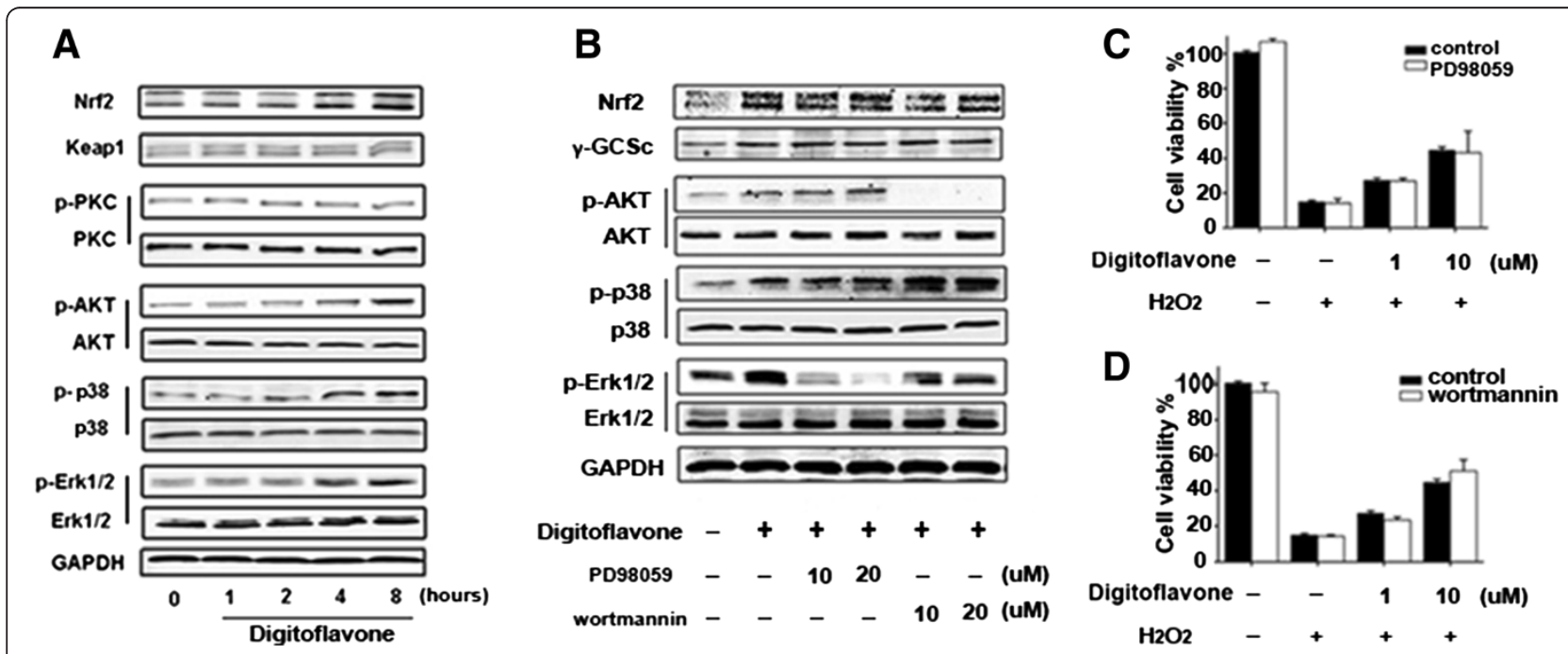

Figure 4 Effects of signaling inhibitors on digitoflavone-induced Nrf2 and $\mathrm{y}$-GCSc expression in Caco-2 cells. (A) Possible mechanism of digitoflavone-induced Nrf2 activation. Caco-2 cells were treated with $10 \mu \mathrm{M}$ digitoflavone for 0, 1, 2, 4, 8 hours, Keap1 expression level and Nrf2 upstream kinases were determined using Western blotting and appropriate specific antibodies. (B) Role of Erk1/2 and PI3K/AKT in digitoflavoneinduced Nrf2 activation. Caco-2 cells were pretreated with various concentration of PD98059 (MEK1/2 inhibitor), wortmannin (for PI3K inhibitor) for 2 hours respectively, then cells were treated with $10 \mu \mathrm{M}$ digitoflavone for an additional 8 hours, Nrf2 and $\gamma$-GCSc expression were determined using Western blotting. (C-D) Caco-2 cells were pretreated with $10 \mu \mathrm{M}$ PD98059 or $10 \mu \mathrm{M}$ wortmannin for 2 hours respectively, then cells were treated with $10 \mu \mathrm{M}$ digitoflavone for an additional 4 hours, anti-oxidative ability was tested with $500 \mu \mathrm{M} \mathrm{H}_{2} \mathrm{O}_{2}$ for an additional $24 \mathrm{~h}$ using MTT assay. The values represent the means \pm SD of triplicate experiments. Significantly different: ${ }^{*} p<0.05,{ }^{* *} p<0.01$. 


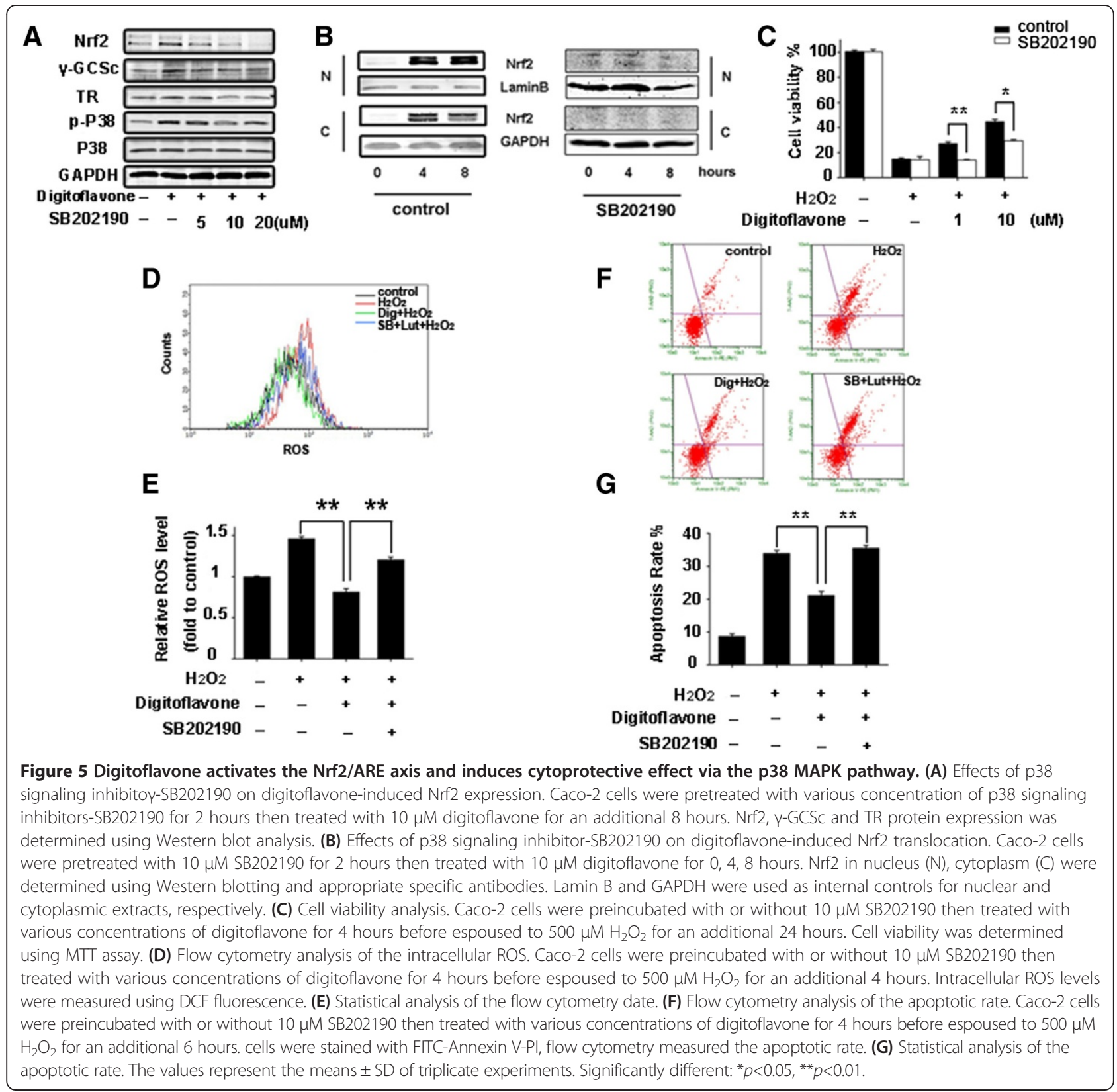

were assessed to demonstrate that the beneficial effect of digitoflavone against tumor progression is attributed to activation of the Nrf2 pathway. Protein expression of Nrf2 and Nrf2 downstream targets TR, $\gamma$-GCSc and $\gamma$-GCSm and mRNA expression of GR, TR, HO- $1, \gamma$-GCSc, $\gamma$ GCSm, NQO-1, UGT1A1 and UGT1A10 were slightly changed in AOM group, indicating induction of the Nrf2 pathway by colon oxidative stress. As expected, treatment with digitoflavone markedly increased the protein levels of Nrf2, TR, $\gamma$-GCSc, $\gamma$-GCSm and HO-1 and mRNA levels of GR, TR, HO-1, $\gamma$-GCSc, $\gamma$-GCSm, NQO-1, UGT1A1 and UGT1A10 (Figure 6E and F). The mRNA Levels of colonic inflammatory cytokines TNF-a, IL-1 $\beta$ and IL-6 were increased in AOM group, and digitoflavone reduced TNF-a, IL- $1 \beta$ and IL- 6 mRNA Levels when compared with AOM group (Figure 6G).

\section{Discussion}

The intestinal epithelium sits at the interface between an organism and its luminal environment, and as such is prone to oxidative damage induced by luminal oxidants. The intestinal epithelial cells, as a barrier between an organism and its intestinal contents, are the first line of defense against frequent exposure to xenobiotics containing chemical toxicants [39]. In the biological defense process, intestinal epithelia express detoxification enzymes 


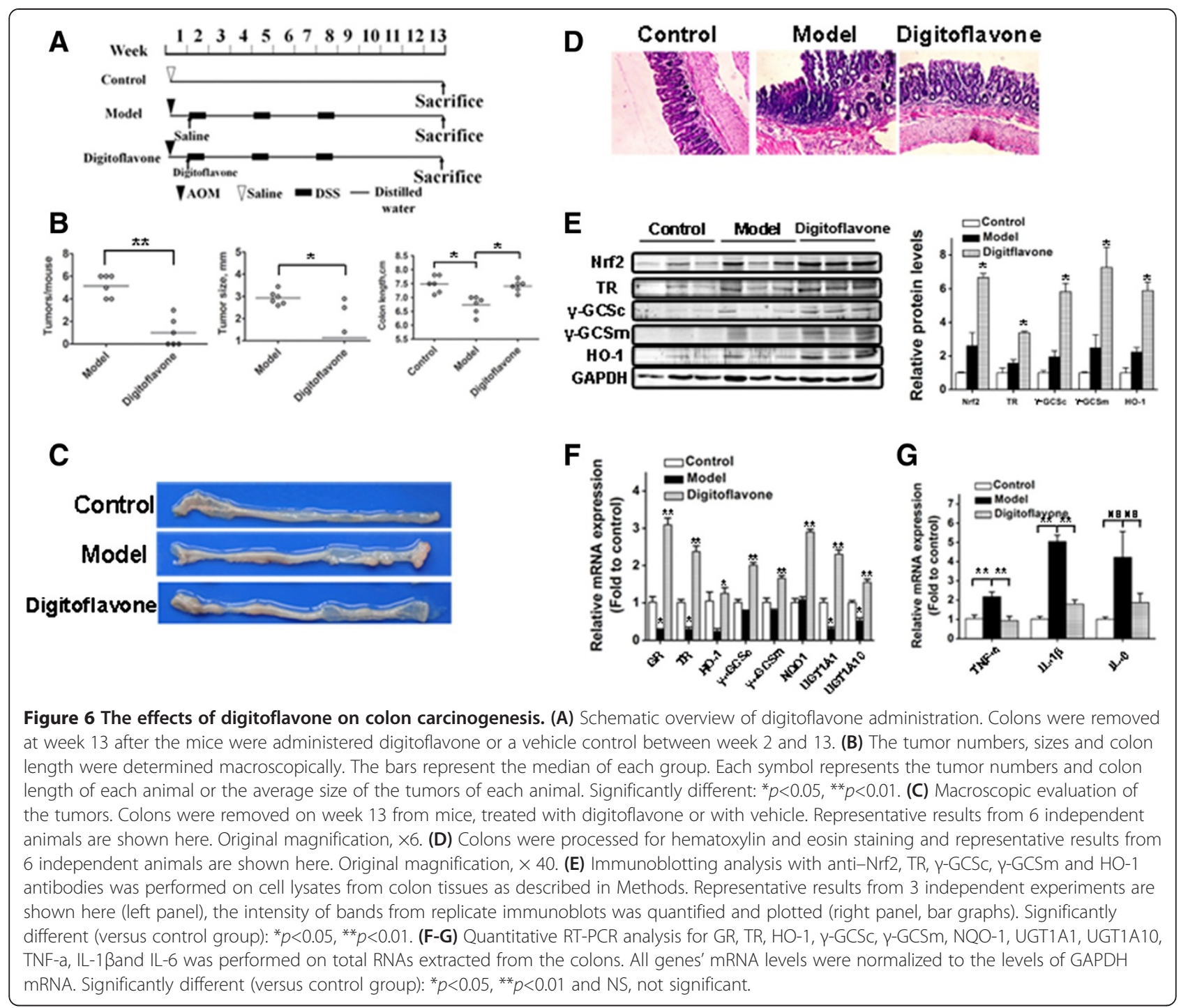

that play important roles in metabolism, detoxification, and exclusion of the xenobiotics [40]. Oxidative stress is associated with mucosal erosions and has a causative role in a variety of gastrointestinal diseases such as Crohn's disease and ulcerative colitis [41,42]. In particular, dietary pro-oxidants may alter the redox status of intestinal cells and provoke inflammatory bowel disease and colon cancer. Epidemiological studies have related a diet rich in fruits and vegetables to the prevention of chronic degenerative diseases linked to oxidative stresses [43]. The antioxidant and chemoprotective properties of food flavonoids or polyphenolic extracts have been widely reported in cultured cells [43], animal models [44], and humans $[45,46]$.

There is a substantial body of scientific literatures that supports a positive role of flavonoids on health [13]. The mechanisms by which the specific flavonoids exert these benefits are under intense investigation. Digitoflavone is a common dietary flavonoid that can be found in a large number of plants and foods and it has been found to possess anti-oxidant, anti-inflammatory/anti-allergic, antitumorigenic, and radical action $[47,48]$. In this study, we demonstrated that the flavones digitoflavone inhibited $\mathrm{H}_{2} \mathrm{O}_{2}$-induced oxidative stress and that this suppression was likely associated with the up-regulation of $\gamma$-GCSc and $\gamma$-GCSm expression through the p38/Nrf2 pathway.

The human colon carcinoma cell line Caco-2 and its derivatives have been widely used in studies on molecular effects of and inter-actions with xenobiotics. The cell line undergoes differentiation during culture, which results in an ileum cell like model system, as well as a model system for cells of the small intestine [49,50]. Using the Caco- 2 cells, we explored the potential molecular mechanisms underlying the chemopreventive and antioxidant effects of digitoflavone, focusing on ARE activation. We found that digitoflavone acts as an ARE 
inducer not only in colon cells Caco-2 s (Figure 1B) and HT-29 (Figure 1C), but also in many other types of cells (Figure 1D-E). Numerous studies have suggested that ARE sequences are involved in regulating the expression of a wide array of antioxidant and detoxifying genes [51], and Nrf2 serves as a master regulator of the ARE-driven cellular defense system against oxidative stresses.

Under normal conditions, Nrf2 is sequestered by Keap1, a substrate adaptor, which helps Cullin 3 ubiquitinate Nrf2 in the cytoplasm, and ARE activation signals (i.e., protein kinase pathway and redox-active components) disrupt the Nrf2/Keap1 complex, leading to phosphorylation and nuclear translocation of Nrf2. Nrf2 then heterodimerizes with small Maf and binds to ARE, eventually resulting in transcriptional activation of the ARE-mediated metabolizing/detoxifying and antioxidant genes [9]. We report in this study that digitoflavone strongly induced Nrf2 protein expression and nucleus accumulation (Figure 2B-D). The rapid accumulation of Nrf2 in the nucleus in response to digitoflavone is consistent with reported results with other Nrf2 activators, such as PEITC [36] and celecoxib [34], and with the Nrf2 degradation inhibitors such as eckol [52].

The Nrf2/ARE pathway activates approximately 100 cytoprotective genes [14]. In this study, digitoflavone elevated the mRNA and protein levels of several AREmediated antioxidant/detoxifying genes in Caco-2 cells (Figure 2A and B). Knockdown of Nrf2 by Nrf2-targeted siRNA markedly suppressed the digitoflavone-induced $\gamma$ GCSc, $\gamma$-GCSm expression (Figure 2D), suggesting that digitoflavone up-regulates Nrf2-dependent activation of the ARE-regulated genes. Nrf2 controls the expression of $\gamma$-GCSc and $\gamma$-GCSm, which together catalyze the rate-limiting step in GSH biosynthesis [53]. Involvement of GSH in the digitoflavone-induced cytoprotection against oxidative injury could not be excluded, because increasing GSH levels would be expected to reduce ROS levels and antagonize the ROS-induced cell death [53]. In this study, treatment of cells with digitoflavone resulted in decreased $\mathrm{H}_{2} \mathrm{O}_{2}$-induced oxidative stress (Figure $3 \mathrm{E}$ and F), and cell death (Figure 3G and $\mathrm{H}$ ).

Activation of Nrf2 involves regulation of protein kinases, which may induce Nrf2 phosphorylation and nuclear translocation [54-57]. The MAPK cascade, PI3K/AKT, and PKC signaling pathways have been reported to influence the Nrf2/ARE pathway [57]. For example, phosphorylation of Nrf2 by PKC promotes its release from Keap1 [6] and inhibition of PI3K attenuates the nuclear translocation of Nrf2 and transcription of ARE-mediated genes [58]. To identify which signal cascade controlled activation of Nrf2 by digitoflavone, we examined the effects of PI3K inhibitor, ERK1/2 inhibitor, and p38 MAPK inhibitor on the digitoflavone-induced Nrf2 up-regulation. Our results demonstrated that PI3K/AKT and ERK1/2 are not involved in the digitoflavone-induced activation of the Nrf2/ARE pathway because their inhibitor had no effect on enhanced digitoflavone-induced Nrf2 up-regulation (Figure 4B-D). On the contrary, inhibition of p38 MAPK by SB202190 leads to decrease of the digitoflavoneinduced Nrf2 up-regulation, indicating that the digitoflavoneinduced Nrf2 activation is dependent on the activation of p38 MAPKs. Inhibition of p38 also abrogated the digitoflavone-induced translocation of Nrf2 to nucleus and the antioxidant defense effect, demonstrating that the crucial role of p38 in the Nrf2-dependent activation of ARE and suggesting that Nrf2 is a downstream effector of p38 kinase in response to digitoflavone treatment.

In vivo experiment we study the chemopreventive role of digitoflavone in AOM-DSS induced colorectal cancer model. Digitoflavone was post-treated after the initiation of stage of colorectal cancer. Compared with AOM group, digitoflavone group shown lower cancer incidents (50\% compare with AMO group 100\%), reduced numbers and size of macroscopical tumors and recovered colon length (Figure 6B-C). General histological observation found that digitoflavone retained a better colonic histoarchitecture with less loss of crypts (Figure 6D). Further protein and mRNA level Analysis indicated the chemopreventive role of digitoflavone may through the activation of Nrf2 and inhibition of inflammation (Figure 6E-G).

In summary, our study demonstrates for the first time that digitoflavone improved the intestinal antioxidant potential through the induction of the main detoxification enzyme $\gamma$-GCSc and $\gamma$-GCSm by a mechanism in which activation of p38 MAPK plays an essential role (Figure 7). In addition, digitoflavone was identified as a potent inducer of Nrf2 expression and translocation providing a support for the involvement of this transcription factor in the induction of $\gamma$-GCSc and $\gamma$-GCSm. The results of the present study add further evidence of the molecular mechanisms that allow digitoflavone to exert protective effects and reaffirm its potential role as a chemopreventive agent in colorectal carcinogenesis.

\section{Material and method \\ Material}

AOM, DSS (MW 36,000-50,000), digitoflavone, SB202190, DCFH-DA [2', 7'-Dichlorofluorescin diacetate], Trypsin, MTT [3-(4, 5-dimethylthiazol-2-yl)-2, 5-diphenyltetrazoli $\mu \mathrm{M}$ bromide], BSO [L-Buthionine-sulfoximine ], DNase-free RNase and SB202190 were obtained from Sigma-aldrich, USA. Digitoflavone was dissolved in dimethyl sulfoxide (DMSO) and was used in all experiments. Maxima ${ }^{\circ}$ SYBR Green/ROX qPCR Master Mix $(2 \times)$ and Maxima ${ }^{\circ}$ First Strand cDNA Synthesis Kit were purchased from Fermentas life science (Fermentas, MBI). PD98059, Wortmannin, Lysis buffer was purchased from Beyotime, China. Primary antibodies (Nrf2 for mouse, $\gamma$-GCSc, $\gamma$-GCSm, TR, HO- 1 , 


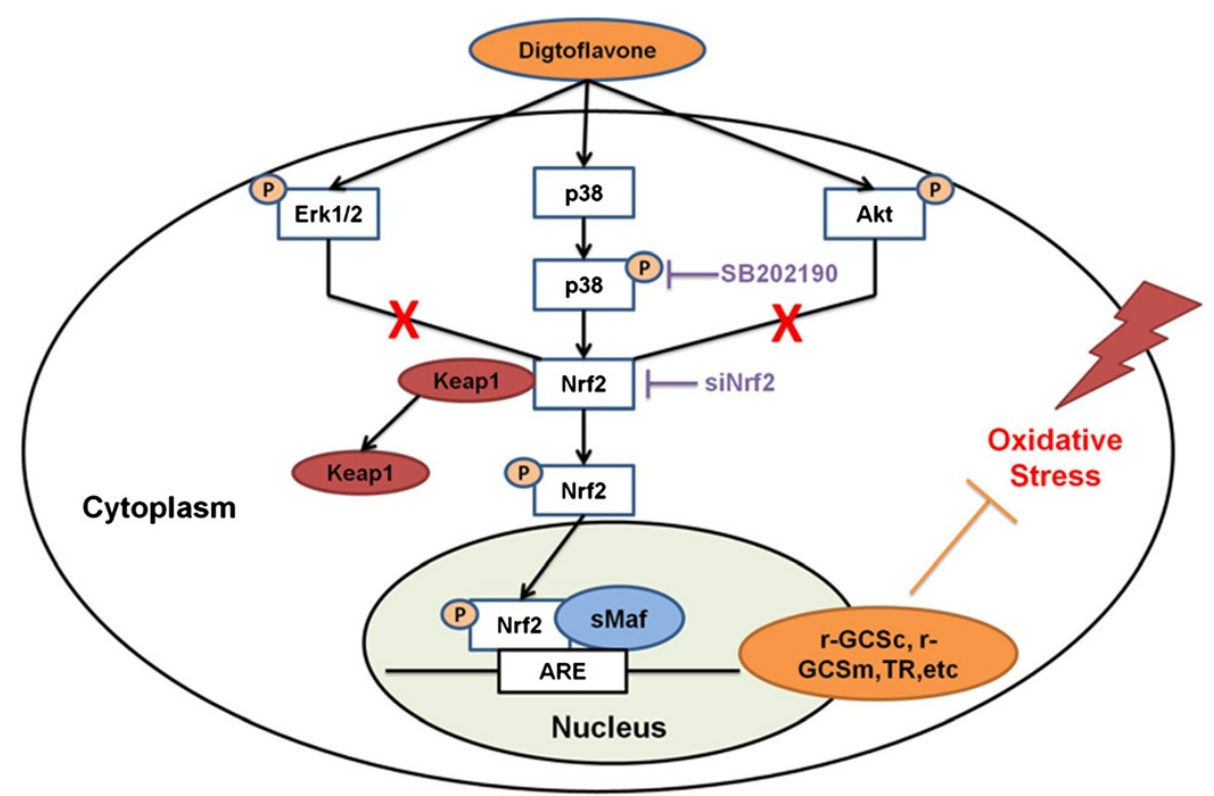

Figure 7 A proposed pathway for digitoflavone-induced Nrf2/ARE-mediated cytoprotective proteins via activation of p38 MAPK signaling. Up-regulation of $\mathrm{y}$-GCSC, $\mathrm{y}$-GCSm explains the cytoprotective effects against oxidative stress in Caco-2 cells.

Keap1, PKC, Lamin B) were obtained from Santa Cruz Biotechnology, CA, USA. Rabbit anti-Nrf2 (for human) was purchased from Abcam, USA. Primary antibodies (p-PKC, ERK1/2, p-ERK1/2, p-p38, p38, AKT and pAKT) were purchased from Cell Signaling Technology, MA, USA. Goat anti-rabbit IgG and goat anti-mouse IgG antibodies were purchased from LI-COR, Lincoln, NE, USA. Rabbit anti-Goat IgG was obtained from KPL, Gaithersbhrg, MD, USA. Monoclonal mouse antiglyceraldehyde-3-phosphate dehydrogease (GAPDH) was obtained from KangChen, China.

\section{Cell lines and cell culture}

Human epithelial colorectal adenocarcinoma cell line Caco-2, Human colon adenocarcinoma grade II cell line HT-29, human liver carcinoma cell line HepG2 ,Human Embryonic Kidney 293 cell HEK-293 were purchased from Cell Bank of Shanghai Institute of Biochemistry and Cell Biology. Cells were cultured in DMEM-medium (for HepG2, HEK-293 cells), MEM-medium (for Caco-2 cells), McCOY's 5A(for HT-29) supplemented with 10\% fetal bovine serum (FBS), $100 \mathrm{U} / \mathrm{ml}$ penicillin and $100 \mu \mathrm{g} / \mathrm{ml}$ streptomycin (all available from Invitrogen, Grand Island, NY, USA). All cultures were maintained in a humidified environment with $5 \% \mathrm{CO}^{2}$ at $37^{\circ} \mathrm{C}$.

\section{Transient transfection and analysis of luciferase reporter gene activity}

We used the luciferase reporter assay to investigate the Nrf2-mediated transcriptional activity of Nrf2. Firstly, 8 copies of antioxidant-responsive element (ARE)-luciferase reporter plasmids were generated using the pGL3 promoter vector (Promega UK). After the plasmids were generated, the DNA sequence of the inserts was verified. The Dual-Luciferase Reporter Assay System (Promega, UK) was used to determine reporter gene activity in transiently transfected cells. Transient transfection was performed in 96-well plates at a cell density of $50 \% \sim 70 \%$ confluence per well. Then the $8 \times$ ARE pGL3 plasmid were cotransfected with the pRL-TK plasmid(transfection ratio of $8 \times$ ARE pGL3:pRL-TK is 10:1), encoding Renilla luciferase as an internal control for transfection efficiency for $24 \mathrm{~h}$ using Lipofectamine 2000 (Invitrogen, Carlsbad, CA, USA) according to the manufacturer's instructions. After transfection, cells were treated with test samples for indicated time, and then cell lysates were prepared for assessment of luciferase activity. Fire fly and Renilla luciferase activities were measured using a luminometer (Centro XS3 LB960, Berthold, Germany) according to the manufacturer's instructions. Relative fire fly luciferase activity was normalized to Renilla luciferase activity and activity was expressed as fold induction after treatment with compounds compared with vehicle control (DMSO).

\section{Cell viability assay}

Cell viability was determined using the MTT assay. Briefly, cells in logarithmic phase were seeded at the density of $70 \sim 80 \%$ confluence per well in 96-well plates at $37^{\circ} \mathrm{C}$ with $5 \% \mathrm{CO}^{2}$ for overnight incubation and treated with appropriate concentrations of test samples for the indicated times. After treatment, $10 \mu \mathrm{lof} 5 \mathrm{mg} / \mathrm{ml}$ MTT was added and the cells were incubated for $4 \mathrm{~h}$ at 
$37^{\circ} \mathrm{C}$. The supernatant was discarded and $100 \mu \mathrm{l}$ of DMSO was added to each well. The mixture was shaken on a mini shaker at room temperature for $10 \mathrm{~min}$ and the spectrophotometric absorbance was measured by Multiskan Spectrum Microplate Reader (Thermo, USA) at $570 \mathrm{~nm}$ and $630 \mathrm{~nm}$ (absorbance $570 \mathrm{~nm}$, reference $630 \mathrm{~nm}$ ). Triplicate experiments were performed in a parallel manner for each concentration point and the results were presented as mean $\pm \mathrm{SD}$. The net $A_{570 \mathrm{~nm}}-A_{630 \mathrm{~nm}}$ was taken as the index of cell viability. The net absorbance from the wells of cells cultured with DMSO was taken as the $100 \%$ viability value. The percent viability of the treated cells was calculated by the formula: \% viability $=\left(A_{570 \mathrm{~nm}}-A_{630 \mathrm{~nm}}\right)$ treated $/$ $\left(A_{570 \mathrm{~nm}}-A_{630 \mathrm{~nm}}\right)_{\text {control }} \times 100 \%$.

\section{SDS -PAGE and Western blot analysis}

Caco-2 cells were cultured in MEM and then treated with test samples for indicated time. Proteins were isolated by lysis buffer (Beyotime, China) and measured using the Nanodrop 1000 Spectrophotometer (Thermo, USA). Protein samples were separated on $10 \%$ SDSpolyacrylamide gels (SDS-PAGE) and transferred onto the PVDF membranes (Millipore, USA). After blocked with $1 \%$ BSA in TBST for $2 \mathrm{~h}$, membranes were incubated with primary antibodies overnight at $4^{\circ} \mathrm{C}$. Blots were washed and incubated with secondary antibodies for $1 \mathrm{~h}$ at room temperature. Membranes were again washed three times with TBST and were scanned with an Odyssey infrared fluorescent scanner (LI-COR) and analyzed with Odyssey software version 3.

\section{Determination of cellular reduced glutathione (GSH) content}

Caco-2 cells were treated with various concentrations of digitoflavone $(1-15 \mu \mathrm{M})$ or vehicle control (DMSO). After $8 \mathrm{~h}$ incubation, the cellular GSH and GSSG were quantified using GSH/GSSG-Glo Assay kit (Promega) according to the manufacturer's protocol. GSH and GSSG levels were normalized to protein concentrations and the GSH/ GSSG ratio was calculated.

\section{Immunofluorescence staining}

Cells in logarithmic phase were seeded in logarithmic phase were seeded at the density of $70 \sim 80 \%$ confluence per well into 24-well chamber slides. After treatment with test samples for the indicated times, cells were fixed with cold $4 \%(\mathrm{w} / \mathrm{v})$ paraformaldehyde for $20 \mathrm{~min}$, rehydrated in PBS for $15 \mathrm{~min}$, and permeabilized in $0.1 \%(\mathrm{w} / \mathrm{v})$ TritonX-100 at room temperature for $10 \mathrm{~min}$. After being washed with PBS, the cells were blocked unspecific fluorescence with $3 \% \mathrm{BSA}$ for 1 hour and then incubated with primary antibody at $4^{\circ} \mathrm{C}$ overnight followed by Texas Red-conjugated secondary antibody for $1 \mathrm{~h}$ at room temperature. The images of Nrf2 with Texas Red staining were captured using a fluorescence microscope.

\section{Preparation of nuclear extract proteins}

Nuclear extract protein was prepared according manufactory's instruction (Thermo, USA). Briefly, after treatment with digitoflavone for indicated times, Caco-2 cells were harvested, washed with PBS, centrifuged, and resuspended in ice-cold buffer CERI. After $10 \mathrm{~min}$ of incubation on ice, cells were added with ice-cold CERII and centrifuged again, the supernatant (cytoplasmic extract) was immediately transferred to a clean pre-chilled tube. The insoluble (pellet) fraction was resuspended with NER, and vortex for 15 seconds every $10 \mathrm{~min}$ for a total $40 \mathrm{~min}$. The tube was centrifuged and the supernatant (nuclear extract) was immediately transferred to a clean pre-chilled tube. The cytoplasmic and nuclear extract protein was stored at $-80^{\circ} \mathrm{C}$ until use. For Western blot analysis, LaminB and GAPDH were used as internal controls for nuclear and cytoplasmic extracts, respectively.

\section{Real-time reverse transcription -polymerase chain reaction (RT-PCR)}

Caco-2 cells were treated with different concentrations of digitoflavone for indicated times, then treated cells were washed with PBS, total RNA was extracted from the treated cells using trizol reagent (Invitrogen, Carlsbad, CA) and then RNA was converted to cDNA by reverse transcriptase (Thermo, USA) according to the manufacturer's instruction. Primers used for the reactions were purchased from Genscript and the sequences were listed in Table 1. Real-time qPCR analysis for mRNA expression was performed using SYBR Green probes and an ABI 7500. ALL genes' mRNA expression was normalized against GAPDH expression.

\section{Measurement of ROS}

The production of cellular ROS, mainly $\mathrm{H}_{2} \mathrm{O}_{2}$, was detected using the DCFH-DA fluorescence assay. Briefly, cells were seeded in 24-well plates at the density of $70 \sim$ $80 \%$ confluence per well for overnight incubation. After treatment with appropriate concentrations of test samples, cells were harvested, placed into $1.5 \mathrm{~mL}$ round-bottom polystyrene tubes, and washed with PBS twice. Subsequently, the cells were centrifuged for $5 \mathrm{~min}$ at $400 \times \mathrm{g}$ at room temperature, and the supernate was discarded. The cells were resuspended in $500 \mu \mathrm{L}$ ROS detection solution, stained in the dark at $37^{\circ} \mathrm{C}$ for $30 \mathrm{~min}$, and analyzed by FACScan laser flow cytometer (Guava easycyteHT, Millipore, CA).

\section{Flow cytometric detection of apoptosis}

Caco-2 cells in logarithmic phase at were treated with test samples for indicated time. Then they were harvested, 
Table 1 Primers used for real-time RT-PCR

\begin{tabular}{|c|c|}
\hline Primer & Sequences \\
\hline \multirow[t]{2}{*}{ hNrf2 } & Forward primer, 5'- CATCCAGTCAGAAACCAGTGG \\
\hline & Reverse primer , 5'- GCAGTCATCAAAGTACAAAGCAT \\
\hline \multirow[t]{2}{*}{ hKeap1 } & Forward primer, 5'-CCTTCAGCTACACCCTGGAG \\
\hline & Reverse primer, 5'-CATGACCTTGGGGTGGATAC \\
\hline \multirow[t]{2}{*}{$h G R$} & Forward primer, 5'-CACGGA GGAGCTGGAGAAC \\
\hline & Reverse primer, 5'- CGACAAAGTCTITTTAACCTCCTT \\
\hline \multirow[t]{2}{*}{ hTR } & Forward primer, 5'-CAGACG GGGAGGCTITTC \\
\hline & Reverse primer, 5'- CCGAGAGCGTTCCTTTCA \\
\hline \multirow[t]{2}{*}{ hHO-1 } & Forward primer, 5'- TCCTGGCTCAGCCTCAAATG; \\
\hline & Reverse primer, 5'- CGTTAAACACCTCCCTCCCC \\
\hline \multirow[t]{2}{*}{ hr-GCSc } & Forward primer, 5'-CTGTTGCAGGAAGGCATTGAT \\
\hline & Reverse primer, 5'- TTCAAACAGTGTCAGTGGGTCTCT \\
\hline \multirow[t]{2}{*}{ hr-GCSm } & Forward primer, 5'- GGCACAGGTAAAACCAAATAGTAAC \\
\hline & Reverse primer, 5'- CAAATTGTTAAGCAAATGCAGTCA \\
\hline \multirow[t]{2}{*}{ hNQO1 } & Forward primer, 5'- GGGATCCACGGGGACATGAATG \\
\hline & Reverse primer, 5'- ATTTGAATTCGGGCGTCTGCTG \\
\hline \multirow[t]{2}{*}{ hUGT1A1 } & Forward primer, 5'-TAAGTGGCTACCCCAAAACG \\
\hline & Reverse primer, 5'- TCCAGCTCCCTTAGTCTCCA \\
\hline \multirow[t]{2}{*}{ hUGT1A10 } & Forward primer, 5'- CGTGTTCTGGGTGGAGTTTG \\
\hline & Reverse primer, 5'- TाTCCCCAAGCATTTCCGG \\
\hline \multirow[t]{2}{*}{ hGAPDH } & Forward primer, 5'- TGCACCACCAACTGCTTAGC \\
\hline & Reverse primer, 5'- GGCATGGACTGTGGTCATGAG \\
\hline \multirow[t]{2}{*}{ mGR } & Forward primer, 5'- AGTGCACTCGGAATTCATGC \\
\hline & Reverse primer, 5'- CAATCAGGATGTGTGGAGCG \\
\hline \multirow[t]{2}{*}{ mTR } & Forward primer, 5'- ATCCACAAACAGCGAGGAGA \\
\hline & Reverse primer, 5'- TTGGTCTGCTCTTCATCCGT \\
\hline \multirow[t]{2}{*}{$\mathrm{mHO}-1$} & Forward primer, 5'- GCCACCAAGGAGGTACACAT \\
\hline & Reverse primer, 5'- GCTTGTTGCGCTCTATCTCC \\
\hline \multirow[t]{2}{*}{ mr-GCSC } & Forward primer, 5'- GGCCACTATCTGCCCAATTG \\
\hline & Reverse primer, 5'- TGTTCTTCAGAGGCTCCAGG \\
\hline \multirow[t]{2}{*}{ mr-GCSm } & Forward primer, 5'- GGAGGGGCTCTTAACTCCAG \\
\hline & Reverse primer, 5'- CTCAACACAGTGCCGAACAA \\
\hline \multirow[t]{2}{*}{ mNQO1 } & Forward primer, 5'- ACAGGTGAGCTGAAGGACTC \\
\hline & Reverse primer, 5'- GTTGTCGTACATGGCAGCAT \\
\hline \multirow[t]{2}{*}{ mUGT1A1 } & Forward primer, 5'- GGAGGCTGTTAGTGTTCCCT \\
\hline & Reverse primer, 5'- CCGTCCAAGTTCCACCAAAG \\
\hline \multirow[t]{2}{*}{ mUGT1A10 } & Forward primer, 5'- GACTCGGGCATTCATCACAC \\
\hline & Reverse primer, 5'- GCGCATGATGTTCTCCTTGT \\
\hline \multirow[t]{2}{*}{ mTNF-a } & Forward primer, 5'- GACCCCTITACTCTGACCCC \\
\hline & Reverse primer, 5'- AGGCTCCAGTGAATTCGGAA \\
\hline \multirow[t]{2}{*}{$m \mid L-1 b$} & Forward primer, 5'- ACTCATTGTGGCTGTGGAGA \\
\hline & Reverse primer, 5'- TTGTTCATCTCGGAGCCTGT \\
\hline \multirow[t]{2}{*}{ mIL-6 } & Forward primer, 5'- CTGCAAGAGACTTCCATCCAGTT \\
\hline & GTAGGGAAGGCCGTGG \\
\hline
\end{tabular}

Table 1 Primers used for real-time RT-PCR (Continued)

\begin{tabular}{ll}
\hline mGAPDH & Forward primer, 5'- CTCCCACTCTTCCACCTTCG \\
& Reverse primer, 5'- CCACCACCCTGTTGCTGTAG \\
\hline
\end{tabular}

washed and resuspended with PBS. Apoptotic cells were determined with an FITC Annexin V Apoptosis Detection Kit (BD Biosciences, USA) according to the manufacturer's protocol. Briefly, the cells were washed and subsequently incubated for $15 \mathrm{~min}$ at room temperature in the dark in $100 \mathrm{ul}$ of $1 \times$ binding buffer containing $5 \mathrm{ul}$ of Annexin V-FITC and $5 \mathrm{ul}$ of PI. Afterward, apoptosis was analyzed by FACScan laser flow cytometer (Guava easycyteHT, Millipore, CA).

\section{RNA interference study}

Nrf2-specific short interfering RNA (siRNA) and scramble control siRNA were obtained from RIBOBIO (GuangZhou, China). Transfection was performed using LipofectAMINE 2000, according to the manufacturer's protocol, with Nrf2-specific siRNA SMARTpool L-003755-00-0050; human NFE2L2 (NCBI Accession No. NM006164); target sequences including TCCCGTTTGTAGATGACAA, GA GAAAGAATTGCCTGTAA and GCAACAGGACATTGAGCAA. Briefly, cells were transfected with $10 \mathrm{nmol} / \mathrm{L}$ siRNAs directed against Nrf2 and non-targeting scramble control siRNA for $48 \mathrm{~h}$, followed by treatment with the test samples for the indicated times. The cells were harvested and the protein status, MTT test and flow cytometry analysis.

\section{Animal experiments}

All animal experiments were conducted in accordance with the NIH Guidelines for the Care and Use of Laboratory Animals. Pathogen-free 8- to 12-week old C57BL/6 male mice were housed in a temperature-controlled room $\left(22^{\circ} \mathrm{C}\right)$ with a controlled 12-h light/dark cycle. The mice were given free access to diet and water during the course of experiments. They were allowed to adapt to the Experimental Animal Laboratory for 1 week before beginning the experiment. Mice were injected intraperitoneally with $10 \mathrm{mg} / \mathrm{kg}$ body weight of AOM dissolved in physiological saline. One week later, $2 \%$ DSS was given in the drinking water over 7 days, followed by 14 days of regular water. This cycle was repeated a total of 3 times. Body weight was measured every week, and the animals were sacrificed at week 13 for macroscopical inspection, histological analysis, and total RNA and protein extraction. In digitoflavone group, digitoflavone at $50 \mathrm{mg} / \mathrm{kg}$ dose suspended in $0.5 \%$ carboxymethyl cellulose (CMC) was given as gavage to mice and mice of control group and $\mathrm{AOM}$ group were given $0.2 \mathrm{~mL} 0.5 \% \mathrm{CMC}$ solution every day from week 2 to week 13 (Figure 6A). 


\section{Statistical analysis}

Results are expressed as mean \pm SD. Statistical tests were performed using SPSS 15.0. Unpaired Student $t$ tests were used to compare the means of two groups. For multiple comparisons between groups, a one-way ANOVA was performed to detect statistical differences. Differences within the ANOVA were determined using a Tukey's posthoc test. $\mathrm{P}$ value of less than 0.05 was considered to be statistically significant.

\section{Abbreviations \\ ABCC: ATP-binding cassette, subfamily C member; AOM: Azoxymethane; AKR1C: Aldo-ketoreductase family member; ARE: Antioxidant-response element; DCFH-DA: $2^{\prime}, 7^{\prime}$-chloro fluorescein diacetate; DMSO: Dimethyl sulfoxide; DSS: Dextran sodium sulfate; $\gamma$-GCSc: $\gamma$-glutamylcysteine synthetase catalytic subunit; $\gamma$-GCSm: $\gamma$-glutamylcysteine synthetase modifier subunit; GR: Glutathione reductase; HO-1: Heme oxygenase-1; Keap1: Kelch-like ECH-associated protein 1; MAPK: Mitogen-activated protein kinases; MTT: 3-(4,5-dimethylthiazol-2-yl)-2,5-diphenyltetrazolium bromide; NQO-1: NAD (P)H:quinone oxidoreductase; Nrf2: NF-E2-related factor 2; \\ PI3K: Phosphatidylinositol 3-kinase; PKC: Protein kinase C; ROS: Reactive oxygen species; TR: Thioredoxin reductase; UGT1A1: UDP glucuronosyltransferase 1 family, polypeptide A1.}

\section{Competing interests}

The authors disclose no conflicts.

\section{Authors' contributions}

YY: Conception and design, acquisition of data, analysis and interpretation of data, writing of the manuscript. XC: Acquisition of data, analysis and interpretation of data. JY: Analysis and interpretation of data. RE: Statistical analysis. XS: Acquisition of data, analysis and interpretation of data, proof-reading of the manuscript. $\mathrm{CH}$ : Development of methodology, revision of the manuscript. ZY: Technical support, analysis and interpretation of data. XX: Conception and design, interpretation of data, revision of the manuscript. WL: Statistical analysis. PC: Obtained funding, conception and design, study supervision, revision of the manuscript. All authors read and approved the final manuscript.

\section{Acknowledgement}

This work was supported by National Natural Science Foundation of China (No.81274150, 81374018, 81202967, 30873410), the Open Project Program of State Key Laboratory of Natural Medicines, China Pharmaceutical University (No.SKLNMKF201301, No.SKLNMKF201203), and Jiangsu Province's Outstanding Leader Program of Traditional Chinese Medicine. We thank Chung S. Yang, Department of Chemical Biology and Center for Cancer Prevention Research, The State University of New Jersey, for his instructive advice and useful suggestions.

Received: 9 December 2013 Accepted: 1 March 2014

Published: 6 March 2014

\section{References}

1. Klaunig JE, Kamendulis LM: The role of oxidative stress in carcinogenesis. Annu Rev Pharmacol Toxicol 2004, 44:239-267.

2. Acharya A, Das I, Chandhok D, Saha T: Redox regulation in cancer: a double-edged sword with therapeutic potential. Oxid Med Cell Longev 2010, 3:23-34

3. Almenier HA, Al Menshawy HH, Maher MM, Al Gamal S: Oxidative stress and inflammatory bowel disease. Front Biosci (Elite Ed) 2012, 4:1335-1344

4. Balkwill F, Mantovani A: Inflammation and cancer: back to Virchow? Lancet 2001, 357:539-545.

5. Jaiswal AK: Nrf2 signaling in coordinated activation of antioxidant gene expression. Free Radic Biol Med 2004, 36:1199-1207.

6. Huang HC, Nguyen T, Pickett CB: Phosphorylation of Nrf2 at Ser-40 by protein kinase $C$ regulates antioxidant response element-mediated transcription. J Biol Chem 2002, 277:42769-42774.

7. Kwak MK, Kensler TW: Targeting NRF2 signaling for cancer chemoprevention. Toxicol Appl Pharmacol 2010, 244:66-76.
8. Klaunig JE, Kamendulis LM, Hocevar BA: Oxidative stress and oxidative damage in carcinogenesis. Toxicol Pathol 2010, 38:96-109.

9. Ramos-Gomez M, Kwak MK, Dolan PM, Itoh K, Yamamoto M, Talalay P, Kensler TW: Sensitivity to carcinogenesis is increased and chemoprotective efficacy of enzyme inducers is lost in nrf2 transcription factor-deficient mice. Proc Natl Acad Sci U S A 2001, 98:3410-3415.

10. Gulcin I: Antioxidant activity of food constituents: an overview. Arch Toxicol 2012, 86:345-391.

11. Hu ML: Dietary polyphenols as antioxidants and anticancer agents: more questions than answers. Chang Gung Med J 2011, 34:449-460.

12. Ross JA, Kasum CM: Dietary flavonoids: bioavailability, metabolic effects, and safety. Annu Rev Nutr 2002, 22:19-34.

13. Crozier A, Jaganath IB, Clifford MN: Dietary phenolics: chemistry, bioavailability and effects on health. Nat Prod Rep 2009, 26:1001-1043.

14. Masella R, Di Benedetto R, Vari R, Filesi C, Giovannini C: Novel mechanisms of natural antioxidant compounds in biological systems: involvement of glutathione and glutathione-related enzymes. J Nutr Biochem 2005, 16:577-586

15. Neuhouser ML: Dietary flavonoids and cancer risk: evidence from human population studies. Nutr Cancer 2004, 50:1-7.

16. Miean KH, Mohamed S: Flavonoid (myricetin, quercetin, kaempferol, luteolin, and apigenin) content of edible tropical plants. J Agric Food Chem 2001, 49:3106-3112.

17. Gates MA, Tworoger SS, Hecht JL, De Vivo I, Rosner B, Hankinson SE: A prospective study of dietary flavonoid intake and incidence of epithelial ovarian cancer. Int J Cancer 2007, 121:2225-2232.

18. Sun $T, X u Z, W u C T$, Janes M, Prinyawiwatkul W, No HK: Antioxidant activities of different colored sweet bell peppers (Capsicum annuum L.). J Food Sci 2007, 72:S98-S102

19. Harborne JB, Williams CA: Advances in flavonoid research since 1992. Phytochemistry 2000, 55:481-504.

20. Ueda $\mathrm{H}$, Yamazaki $\mathrm{C}$, Yamazaki M: Luteolin as an anti-inflammatory and anti-allergic constituent of Perilla frutescens. Biol Pharm Bull 2002, 25:1197-1202

21. Yamashita N, Kawanishi S: Distinct mechanisms of DNA damage in apoptosis induced by quercetin and luteolin. Free Radic Res 2000, 33:623-633.

22. Cai X, Ye T, Liu C, Lu W, Lu M, Zhang J, Wang M, Cao P: Luteolin induced G2 phase cell cycle arrest and apoptosis on non-small cell lung cancer cells. Toxicol In Vitro 2011, 25:1385-1391.

23. Cai X, Lu W, Ye T, Lu M, Wang J, Huo J, Qian S, Wang X, Cao P: The molecular mechanism of luteolin-induced apoptosis is potentially related to inhibition of angiogenesis in human pancreatic carcinoma cells. Oncol Rep 2012, 28:1353-1361

24. Cai X, Lu W, Yang Y, Yang J, Ye J, Gu Z, Hu C, Wang X, Cao P: Digitoflavone Inhibits IkappaBalpha Kinase and Enhances Apoptosis Induced by TNFalpha through Downregulation of Expression of Nuclear Factor kappaB-Regulated Gene Products in Human Pancreatic Cancer Cells. PLoS One 2013, 8:e77126

25. Shimoi K, Masuda S, Furugori M, Esaki S, Kinae N: Radioprotective effect of antioxidative flavonoids in gamma-ray irradiated mice. Carcinogenesis 1994, 15:2669-2672.

26. Kaspar JW, Niture SK, Jaiswal AK: Nrf2:INrf2 (Keap1) signaling in oxidative stress. Free Radic Biol Med 2009, 47:1304-1309.

27. Motohashi H, O'Connor T, Katsuoka F, Engel JD, Yamamoto M: Integration and diversity of the regulatory network composed of Maf and CNC families of transcription factors. Gene 2002, 294:1-12.

28. Klaunig JE, Wang Z, Pu X, Zhou S: Oxidative stress and oxidative damage in chemical carcinogenesis. Toxicol Appl Pharmacol 2011, 254:86-99.

29. Lee JS, Surh YJ: Nrf2 as a novel molecular target for chemoprevention. Cancer Lett 2005, 224:171-184.

30. Sharma S, Stutzman JD, Kelloff GJ, Steele VE: Screening of potential chemopreventive agents using biochemical markers of carcinogenesis. Cancer Res 1994, 54:5848-5855.

31. Cerutti PA: Prooxidant states and tumor promotion. Science 1985, 227:375-381.

32. Zorov DB, Filburn CR, Klotz LO, Zweier JL, Sollott SJ: Reactive oxygen species (ROS)-induced ROS release: a new phenomenon accompanying induction of the mitochondrial permeability transition in cardiac myocytes. J Exp Med 2000, 192:1001-1014.

33. Martin D, Rojo Al, Salinas M, Diaz R, Gallardo G, Alam J, De Galarreta CM, Cuadrado A: Regulation of heme oxygenase-1 expression through the phosphatidylinositol 3-kinase/Akt pathway and the Nrf2 transcription 
factor in response to the antioxidant phytochemical carnosol. $J$ Biol Chem 2004, 279:8919-8929.

34. Hamdulay SS, Wang B, Birdsey GM, Ali F, Dumont O, Evans PC, Haskard DO, Wheeler-Jones CP, Mason JC: Celecoxib activates Pl-3 K/Akt and mitochondrial redox signaling to enhance heme oxygenase-1-mediated anti-inflammatory activity in vascular endothelium. Free Radic Biol Med 2010, 48:1013-1023.

35. Kweon MH, In Park Y, Sung HC, Mukhtar H: The novel antioxidant 3-O-caffeoyl-1-methylquinic acid induces Nrf2-dependent phase II detoxifying genes and alters intracellular glutathione redox. Free Radic Biol Med 2006, 40:1349-1361.

36. Xu C, Yuan X, Pan Z, Shen G, Kim JH, Yu S, Khor TO, Li W, Ma J, Kong AN: Mechanism of action of isothiocyanates: the induction of ARE-regulated genes is associated with activation of ERK and JNK and the phosphorylation and nuclear translocation of Nrf2. Mol Cancer Ther 2006, 5:1918-1926.

37. Ogborne RM, Rushworth SA, O'Connell MA: Epigallocatechin activates haem oxygenase-1 expression via protein kinase Cdelta and Nrf2. Biochem Biophys Res Commun 2008, 373:584-588.

38. Rushworth SA, Ogborne RM, Charalambos CA, O'Connell MA: Role of protein kinase $\mathrm{C}$ delta in curcumin-induced antioxidant response element-mediated gene expression in human monocytes. Biochem Biophys Res Commun 2006, 341:1007-1016.

39. Carriere V, Chambaz J, Rousset M: Intestinal responses to xenobiotics. Toxicol In Vitro 2001, 15:373-378.

40. Xu C, Li CY, Kong AN: Induction of phase I, II and III drug metabolism/ transport by xenobiotics. Arch Pharm Res 2005, 28:249-268.

41. Pravda J: Radical induction theory of ulcerative colitis. World J Gastroenterol 2005, 11:2371-2384

42. Rezaie A, Parker RD, Abdollahi M: Oxidative stress and pathogenesis of inflammatory bowel disease: an epiphenomenon or the cause? Dig Dis Sci 2007, 52:2015-2021.

43. Ramos S: Cancer chemoprevention and chemotherapy: dietary polyphenols and signalling pathways. Mol Nutr Food Res 2008, 52:507-526.

44. Mukhtar $\mathrm{H}$, Ahmad N: Tea polyphenols: prevention of cancer and optimizing health. Am J Clin Nutr 2000, 71:1698S-1702S. discussion 1703S-1694S.

45. Ahn WS, Yoo J, Huh SW, Kim CK, Lee JM, Namkoong SE, Bae SM, Lee IP: Protective effects of green tea extracts (polyphenon E and EGCG) on human cervical lesions. Eur J Cancer Prev 2003, 12:383-390.

46. Bettuzzi S, Rizzi F, Belloni L: Clinical relevance of the inhibitory effect of green tea catechins (GtCs) on prostate cancer progression in combination with molecular profiling of catechin-resistant tumors: an integrated view. Pol J Vet Sci 2007, 10:57-60.

47. Ashokkumar P, Sudhandiran G: Protective role of luteolin on the status of lipid peroxidation and antioxidant defense against azoxymethane-induced experimental colon carcinogenesis. Biomed Pharmacother 2008, 62:590-597.

48. Galati G, Moridani MY, Chan TS, O'Brien PJ: Peroxidative metabolism of apigenin and naringenin versus luteolin and quercetin: glutathione oxidation and conjugation. Free Radic Biol Med 2001, 30:370-382.

49. Meunier $V$, Bourrie $M$, Berger $Y$, Fabre $G$ : The human intestinal epithelial cell line Caco-2; pharmacological and pharmacokinetic applications. Cell Biol Toxicol 1995, 11:187-194.

50. Sambuy Y, De Angelis I, Ranaldi G, Scarino ML, Stammati A, Zucco F: The Caco-2 cell line as a model of the intestinal barrier: influence of cell and culture-related factors on Caco-2 cell functional characteristics. Cell Biol Toxicol 2005, 21:1-26.

51. Wasserman WW, Fahl WE: Functional antioxidant responsive elements. Proc Natl Acad Sci U S A 1997, 94:5361-5366.

52. Kim KC, Kang KA, Zhang R, Piao MJ, Kim GY, Kang MY, Lee SJ, Lee NH, Surh YJ, Hyun JW: Up-regulation of Nrf2-mediated heme oxygenase-1 expression by eckol, a phlorotannin compound, through activation of Erk and PI3K/Akt. Int J Biochem Cell Biol 2010, 42:297-305.

53. Davis W Jr, Ronai Z, Tew KD: Cellular thiols and reactive oxygen species in drug-induced apoptosis. J Pharmacol Exp Ther 2001, 296:1-6.

54. Giudice A, Montella M: Activation of the Nrf2-ARE signaling pathway: a promising strategy in cancer prevention. Bioessays 2006, 28:169-181.

55. Zhang $Y$, Gordon GB: A strategy for cancer prevention: stimulation of the Nrf2-ARE signaling pathway. Mol Cancer Ther 2004, 3:885-893.

56. Pi J, Bai Y, Reece JM, Williams J, Liu D, Freeman ML, Fahl WE, Shugar D, Liu J, Qu W, Collins S, Waalkes MP: Molecular mechanism of human Nrf2 activation and degradation: role of sequential phosphorylation by protein kinase CK2. Free Radic Biol Med 2007, 42:1797-1806.
57. Kwak MK, Wakabayashi N, Kensler TW: Chemoprevention through the Keap1-Nrf2 signaling pathway by phase 2 enzyme inducers. Mutat Res 2004, 555:133-148.

58. Lee JM, Hanson JM, Chu WA, Johnson JA: Phosphatidylinositol 3-kinase, not extracellular signal-regulated kinase, regulates activation of the antioxidant-responsive element in IMR-32 human neuroblastoma cells. J Biol Chem 2001, 276:20011-20016.

doi:10.1186/1476-4598-13-48

Cite this article as: Yang et al:: Chemoprevention of dietary digitoflavone on colitis-associated colon tumorigenesis through inducing Nrf2 signaling pathway and inhibition of inflammation. Molecular Cancer 2014 13:48.

\section{Submit your next manuscript to BioMed Central and take full advantage of:}

- Convenient online submission

- Thorough peer review

- No space constraints or color figure charges

- Immediate publication on acceptance

- Inclusion in PubMed, CAS, Scopus and Google Scholar

- Research which is freely available for redistribution 